\title{
(1) \\ Validation and Examination of the Ohio Youth Assessment System With Juvenile Sex Offenders \\ Jordan Papp
}

University of Michigan

Christina A. Campbell

William T. Miller

University of Cincinnati

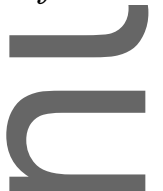

\section{Research Summary}

In this study, we examined the use of an actuarial risk assessment tool-the Ohio Youth Assessment System-Disposition Tool (OYAS-Disposition Tool)—with juvenile sex offenders. Specifically, the main goals of the study were to (a) examine the predictive validity of the tool with sex offenders and (b) explore the nature of the use of professional discretion used to override the tool. The sample consisted of 3,235 youth from a large juvenile county court in the Midwest. The results indicated that the OYAS-Disposition Tool was a significantly better option for predicting general recidivism for sex offenders than it was for non-sex offenders.

The tool was also an effective method for predicting sexual recidivism. Most importantly, however, the use of professional overrides significantly reduced the ability of researchers to apply the tool to predict new court petitions and adjudications to nonsignificant levels.

Direct correspondence to Jordan Papp, Institute for Social Research, University of Michigan, 426 Thompson Avenue, Ann Arbor, MI 48104 (e-mail: pappjr@mail.uc.edu).

This is the author manuscript accepted for publication and has undergone full peer review but has not been through the copyediting, typesetting, pagination and proofreading process, which may lead to differences between this version and the Version of Record. Please cite this article as doi: 10.1111/1745-9133.12464.

This article is protected by copyright. All rights reserved. 
Finally, several justifications were commonly used for overrides: treatment needs, offense seriousness, and use of an alternative sex-offender-specific assessment.

\section{Policy Implications}

The findings in this study highlight several important policy implications that would improve the assessment process for juvenile sex offenders. First, agencies using specialized risk assessments designed for sex offenders may consider applying a general risk assessment tool to identify a broader set of criminogenic needs and to predict risk of general recidivism. Second, there is a need to evaluate policies and practices that allow for the use of professional discretion with sex offenders given that they reduce the predictive validity of the risk tool evaluated. The high rate of overrides for juvenile sex offenders and justification for their use go against best practices in corrections. For instance, overrides were often justified based on offense seriousness; however, focusing on evidence-based criminogenic risk factors provides the best accuracy in predicting future offending. In this study, we call into question court policies that allow for overrides based on crime type or based on a practitioner's professional judgment concerning a juvenile's level of service needs. Last, agencies should consider validation research within their agency before full adoption of a general risk assessment tool to quell concerns about the use and accuracy of a tool for special populations like juvenile sex offenders.

\section{Keyworerds}

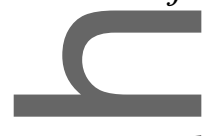

risk assessment, sex offenders, overrides, professional discretion

The successful supervision and treatment of juvenile sex offenders depends on the ability to predict with accuracy the risk that they pose for reoffending (Worling \& Langstrom, 2008) as it is estimated that approximately $20 \%$ of sex offenses are committed by persons younger 
than 18 years of age in any given year (Barbaree \& Marshall, 2008). Significant improvements in risk prediction have been made in the past several decades. In fact, actuarial risk assessment has been demonstrated to be one of the best methods of assessing criminogenic risk (Desmarais \& Singh, 2013). Debate continues, however, about the most effective way to design actuarial tools used by researchers to predict recidivism among juvenile sex offenders. Moreover, the amount of research pertaining to juvenile sex offenders is sparse relative to the amount pertaining to their adult counterparts.

The findings from the research available have shown that juvenile sex offenders possess divergent criminogenic risk factors that are much less common among nonsex offenders (Prentky \& Righthand, 2003; Worling \& Langstrom, 2008). For example, deviant sexual interests are a risk factor among juvenile sex offenders, which is not the case for nonsex offenders (Worling \& Curwen, 2000). For this reason, some scholars have questioned the effectiveness of risk assessments that were not designed with sex offenders in mind (Tully, Chou, \& Browne, 2013). Contrary to this argument, some research findings also indicate that risk assessment tools designed to aid in predicting recidivism for general types of offending can aid in predicting recidivism for sex offenders as well (Olver, Stockdale, \& Wormith, 2009; Ragusa-Salerno, Ostermann, \& Thomas, 2013). These inconsistencies demonstrate the importance of continued research into the effectiveness of generally designed risk assessment tools with sex offenders (Baldwin, 2014).

An important aspect of this research topic that requires continued investigation is the distinction between the prediction of sexual and nonsexual recidivism. Researchers have suggested that despite societal perceptions about sex offenders, they are less likely to specialize in sex offending and are more likely to be generalists in terms of offending behavior (Caldwell, 2010). For instance, Caldwell (2010) found that juvenile sex offenders were more likely to recidivate with a nonsexual offense (43\%) than with a sexual offense 
(7\%). Scholars researching adult samples found similarly lower sexual recidivism rates as compared with nonsexual recidivism rates, which shows that this pattern is consistent regardless of age (Hanson \& Bussiere, 1998; Helmus, Hanson, Thornton, Babchishin, \& Harris, 2012). For this reason, use of risk assessment tools that can aid researchers in predicting both sexual and nonsexual recidivism is important. Understanding the prediction of both outeomes has significant implications for the use of risk assessment tools with sex offenders because effective case management is best informed by a tool that can be used to predict bothoutcomes equally well. Alternatively, separate tools could be used to predict recidivism: one focused on predicting sexual recidivism and one focused on predicting general recidivism. Using this strategy may lead to better prediction and identification of criminogenic needs than the use of only one tool.

One tool that was designed for general use across a diverse offender population is the Ohio Youth Assessment System-Disposition Tool (OYAS-Disposition Tool; Latessa, Lovins, \& Ostrowski, 2009). Although scholars have yet to examine the efficacy of this tool with sex offenders, it is still widely used for this purpose, such as statewide in several locations (e.g., Ohio, Arizona, Texas, and Indiana) and by numerous other county-level jurisdictions around the United States (Latessa et al., 2013; Lovins \& Latessa, 2013; McCafferty, 2013).

Furthermore, more research is also needed to understand the role that professional discretion plays in the assessment of sex offenders because past research findings have shown that riskassessment users report low trust in the efficacy of risk assessment with sex offenders as a result of their beliefs that sex offending cannot be predicted (Carns \& Martin, 2011). As a result, Carns and Martin (2011) found that professionals are more likely to override risk assessment used with sex offenders. Overrides in risk assessment take place when a user of the tool decides to change some outcome of the risk assessment, such as adjusting the risk level produced by the tool to match what the user feels is a more accurate 
risk level. Research results have shown, however, that professional discretion typically leads to a reduction in the efficacy of risk assessment (Guay \& Parent, 2017; Wormith, Hogg, \& Guzzo, 2012). As a result, in this study, we will also explore the ways in which professionals justify using overrides with sex offenders and the impact that overrides have on the ability to use the OYAS-Disposition Tool to predict recidivism with accuracy.

\section{Literature Review}

Those that commit sex crimes garner special attention as a group of offenders. They are commonly the target of policies and practices that are exclusive to them (Levenson, 2008). For example, some states have policies designed to make the public aware of youth who have committed-sexual crimes (e.g., sex offender registries). As of 2015, 15 states have juvenile sex offender registries in which the name, address, and photograph of youth adjudicated for sex crimes are published on the Internet (Pew Charitable Trust, 2015). These policies have the effect of further stigmatizing individuals that have committed a sex crime and increase perceptions of fear held among members of the public (Barbaree \& Marshall, 2008;

Levenson, Brannon, Fortney, \& Baker, 2007).

Beyond special interest by the public and policy makers, researchers have also shown a special interest in sex offenders. In terms of risk assessment research, more attention has been spent on sex offenders as a specialized group when compared with any other specialized groups (e.g., offenders with psychopathy; Worling \& Langstrom, 2008). Nevertheless, disagreement remains about the most effective means of assessing criminogenic risk with this group (Baldwin, 2014). Many tools lack validation research in which their efficacy with specialized groups of offenders, such as sex offenders, has been examined. This research is important because findings show that the predictive validity of risk assessment tools can vary depending on the background of an offender (e.g., offense type or demographics; Campbell, 
Papp, Barnes, Onifade, \& Anderson, 2018; Olver et al., 2009). As a result, we lack enough evidence to implement a consistent set of procedures to assess sex offenders in the criminal and juvenile justice systems.

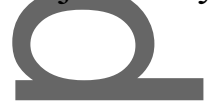

\section{General Risk Assessment Tools}

Diverse riskassessment tools were designed for general use by practitioners seeking to improve their assessment practices. In fact, with so many options available, researchers have published guides intended to aid practitioners in the selection of a risk assessment tool (Bonta, 2002; Latessa \& Lovins, 2010). Some examples of these tools include the Youth Level of Service/Case Management Inventory (YLS/CMI; Hoge, \& Andrews, 2011), Youth Assessment and Screening Instrument (YASI; Orbis Partners, 2007), and OYAS-Disposition Tool (Latessa et al., 2009). The results of validation research have shown that each of these tools can be used to predict reoffending (Baird, Healy, Johnson, Bogie, Dankert, \& Scharenbroch, 2013; McCafferty, 2016; Schwalbe, 2007).

Many risk assessment tools designed for general use measure a similar set of criminogenic risk factors. For example, the three tools mentioned previously all measure what are referred to as the "Central Eight" risk factors for recidivism. Bonta and Andrews (2016) argued that the Central Eight are the most empirically well-supported risk factors for recidivism. They created this list by compiling the results from eight meta-analyses in which predictors of criminality were examined. Using these results, they estimated a mean-weighted effect size of the best predictors from the meta-analyses reviewed. Thus, the following eight risk factors were the best predictors of criminogenic risk: (1) history of antisocial behavior (offense history), (2) antisocial personality, (3) antisocial cognition, (4) antisocial associates, (5) family/marital problems, (6) problems at school/work, (7) lack of prosocial leisure/recreation, and (8) substance abuse. Furthermore, Bonta and Andrews (2016) 
suggested that the utility of these predictors extends to diverse groups of offenders, including juvenile offenders and sex offenders.

Research on general risk assessment tools that use the Central Eight has produced findings that show support for the use of these constructs in risk assessment. Several metaanalyses have been done on the topic. For instance, Olver and colleagues (2009) found a mean-weighted effect size of $r=.32$ between the total score of the Level of Service Inventory (LSI) and general recidivism, whereas Schwalbe (2007) produced a mean weighted area under the curve (AUC) statistic of .64 for the relationship between the total score of the YLS/CMI and general recidivism. In a follow-up study, Schwalbe (2008) also showed that the predictive validity of the YLS/CMI was consistent across male $(r=.26)$ and female $(r=$ .27) youth- Importantly, Olver and colleagues (2009) found that the total score of the LSI was a significant predictor of sexual recidivism $(r=.20)$, which indicates that the utility of the Central Eight might extend to the prediction of sexual recidivism as well. The evidence is limited, however, concerning whether general risk assessment tools are less predictive of sexual recidivism than of general recidivism (Campbell, Anderson, \& Papp, 2018). One such tool is the QYAS-Disposition Tool. This tool was constructed using a prospective research design in which more than 400 correlates of offending were examined to create the list of items seen on the tool currently. So far, research on the OYAS-Disposition Tool has produced results that show support for the validity of the tool and that its ability to predict general recidivism is in line with other well-performing tools. For example, in two studies in which the OYAS-Disposition Tool was examined, scholars found that the total score of the tool correlates with recidivism at a level between $r=.30$ and .32 (Lovins \& Latessa, 2013; McCafferty, 2013). Unpublished validity research results also show that this tool is as predictive of recidivism (Latessa et al., 2009; Latessa, Lovins, \& Lux, 2014) as other commonly used youth risk assessments, such as the YLS/CMI (Schwalbe, 2007). Now that 
the OYAS-Disposition Tool has been validated on general populations of juvenile offenders, the next step is to investigate its utility with specialized offender populations.

\section{Specialized Risk Assessment Tools}

A substantial collection of juvenile risk assessment tools were also specifically designed for use with sex offenders. Two examples include the Juvenile Sex Offender Assessment Protocol (JSOAP; Prentky \& Righthand, 2003) and the Estimate of Risk of Adolescent Sexual Offense Recidivism (ERASOR; Worling, 2004). Risk assessment tools have been designed specifically for juvenile sex offenders because research findings show that they possess a unique set of risk factors. For instance, sex-offender-specific risk assessments are typically focused on factors such as deviant sexual preoccupation and interests. These unique risk factors are assessed on juvenile sex offender risk assessments because models of sex offending diverge from more general theories of offending. For instance, Knight and SimsKnight (2003) laid out a model with three pathways into sexual offending, which include physical and verbal abuse that leads to callousness and disinhibited sexual drive, sexual abuse that leads directly to disinhibition of sexual drive, and early antisocial behavior and aggression that leads to callousness/lack of emotion and ultimately sexual offending. These factors are important to sexual reoffending, but it would be missed on a general assessment not designed to assess risk for sexual recidivism. These factors, however, would be measured on sex-offender-specific assessments, which makes it important to consider using both types of assessments.

In addition to measuring risk factors specific to sex offenders, some specialized risk assessments are also used to measure some Central Eight risk factors commonly found on general tools. For instance, the JSOAP measures factors related to substance abuse, school problems, peer relationships, and attitudes and beliefs. In the manual for the tool, the creators 
stated that the JSOAP is intended to determine risk for both sexual and nonsexual recidivism, which is why the tool includes this wide range of risk factors. In this way, the JSOAP and other sex offender risk assessments are similar in some ways to general risk assessment tools, with the addition of sex offender risk factors.

The findings from validation research on specialized risk assessments have shown that these tools are significant predictors of both sexual and general reoffending. In a metaanalysis, Viljoen, Mordell, and Beneteu (2012) found that both JSOAP and ERASOR predict sexual reoffending $(A U C=.67$ and .66 , respectively $)$ and general reoffending $(A U C=.66$ and .59, respectively) at levels significantly better than chance (even though an AUC of .59 would be considered poor performance for a risk assessment). Also, several Central Eight factors performedjust as well as sex-specific risk factors in terms of predicting sexual recidivism.For instance, impulsivity/antisocial behavior shared a similar association with sexual reoffending $(r=.14)$ compared with sexual drive/preoccupation $(r=.12)$ as measured on the JSOAP. In addition, psychological functioning and family/environment were significant predictors of sexual reoffending ( $r=.13$ and .11 , respectively), whereas sexual interests, drive, and preoccupation were not significant predictors of sexual recidivism on the ERASOR. These findings demonstrate the utility of the Central Eight for predicting both sexual and general recidivism. For this reason, risk assessment tools designed for general use, such as the OYAS, may have utility with sex offenders and therefore require investigation into understanding their predictive validity with this specialized group of offenders.

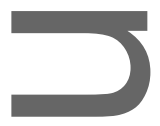

\section{Professional Diseretion and Sex Offenders}

Both the public and criminal justice professionals carry strong beliefs about sex offenders that stigmatize and marginalize this group. For example, many believe that nearly all sex offenders are at a high risk to reoffend and therefore pose a substantial threat to public safety 
(Levenson et al., 2007) even though most research findings show this group tends to score much lower on general risk assessment tools compared with nonsex offenders (Campbell et al., 2018). For instance, Sahlstrom and Jeglic (2008) found that sex offenses committed by juvenile offenders are considered to be just as serious as those committed by adults. In addition, many believe that the criminal and juvenile justice systems should focus on a retributive philosophy for sex offenders (Comartin, Kernsmith, \& Kernsmith, 2009). Researchers have even shown that adult sex offenders who have committed serious crimes (e.g., rape) are deserving of the death penalty (Mancini \& Mears, 2010).

This harsh philosophy surrounding sex offenders has important implications for the way that sex offenders are managed in the criminal and juvenile justice systems. As it relates to risk assessment research, the findings from two studies have shown that sex offenders are more likely to receive discretionary overrides (Carns \& Martin, 2011; Wormith, Hogg, \& Guzzo, 2013). Discretionary overrides occur when a user of a risk assessment tool decides to supersede the outcome of the assessment and adjust the risk assessment in accordance with his or her professional opinion. ${ }^{1}$

Most importantly, the results of past research on the use of professional discretion show that sex offenders make up the group most likely to receive overrides. Wormith and colleagues (2013) found that among a sample of 26,450 adult offenders in Canada, $35.1 \%$ of sex offenders received an override on the Level of Service/Case Management Inventory (LS/CMI). In contrast, $15.1 \%$ of offenders convicted of something other than a sex crime received an override. In another study, Carns and Martin (2011) found that juvenile sex offenders were more likely to receive overrides on the YLS/CMI. What is more, Carns and

\footnotetext{
${ }^{1}$ Allowing overrides in risk assessment can turn assessment into a process that resembles structured professional judgment. Using this method, evaluators follow a general set of guidelines of how to conduct an assessment. Then the evaluator must make decisions based on the information that they gather. Research findings show that this method is favored by practitioners because it still provides them with the ability to use their professional judgment (Judge, Quayle, O'Rourke, Russell, \& Darjee, 2014) and is significantly better at predicting reoffending versus random chance (Lawing, Childs, Frick, \& Vincent, 2017).
} 
Martin (2011) conducted follow-up interviews with officers to gather more information about the nature of the use of overrides. These interviews led to the important finding that users of believe that the YLS/CMI was able to predict sexual recidivism. For this reason, the officers reported that they felt it was necessary to use their discretion more widely during the assessment of sex offenders.

Although the findings from the two studies discussed provide important insights into the use of Overrides with sex offenders, further research is still needed to answer vital questions about overrides used with sex offenders that could have important implications for policy. First, scholars need to investigate further the ways in which risk assessment users justify the use of overrides for sex offenders. There could be numerous reasons used in jurisdictions outside of where Carns and Martins' (2011) study took place that impact the reasons that risk assessment users invoke professional discretion. For example, other jurisdictions may have a policy in which the use of overrides with sex offenders is required. It could also be possible that some jurisdictions carry a more retributive philosophy and use overrides with sex offenders as a means of exacting sanctions that require increased supervision and treatment. ${ }^{2}$ Second, it is important to examine the influence of overrides on the predictive validity of risk assessment because researchers have found that predictive validity of a tool is usually harmed when overrides are used to adjust the risk score or level of a risk assessment (Guay \& Parent, 2017; Wormith et al., 2012). Overrides may be especially harmful for predictive validity when examining sex offenders because of their high rate of use with this group (Carns \& Martin, 2011; Wormith et al., 2013). Moreover, a scant amount of research on overrides has been conducted with youth risk assessment. In fact, in the studies

\footnotetext{
${ }^{2}$ No data were collected in this study directly measuring the policies, procedures, or overarching treatment/punishment philosophy of the jurisdiction in this study in relation to the use of overrides. Therefore, few assumptions can be made prior to the analyses conducted as follows. Rather, any information about policies, procedures, or philosophy must be gleaned from the results from the content analysis.
}

This article is protected by copyright. All rights reserved. 
that were reviewed by Guay and Parent (2017) and Wormith and colleagues (2013), the researchers used adult samples. They were reviewed here, though, to give a sense of what has been found in past research and to show the paucity of research that exists with youth samples. Therefore, this research is necessary and important for informing policy that monitors and controls the use of overrides as it may improve the ability to predict offending for sex offenders by reigning in professional discretion.

\section{Method}

\section{Procedure}

Data for this study were collected primarily from court records held at a large juvenile court in a midwestern county. The county the court is located in has a population of approximately 1.3 million according to 2010 decennial U.S. Census estimates. Of the county's residents, most are Black (23.2\%) or non-Hispanic White (63.4\%). There are few Hispanics $(5.5 \%)$ or other racial groups. The county has a mixture of urban, suburban, and rural areas with the largest, mostly urban, city comprising approximately three quarters of the population. Finally, Uniform Crime Reporting (UCR) data from 2010 indicate that crime rates are higher in the county compared with the national average (i.e., 512 and 5,276 for violent and property crimes, respectively, per 100,000 residents in the county as compared with 404 and 2,945 nationally).

Court records were sampled based on several inclusion criteria. First, youth had to receive an OYAS-Disposition Tool assessment between January 1, 2010 and December 31, 2016. The beginning date of the study was chosen because it closely coincides with the full implementation of the OYAS-Disposition Tool in the court in the study, and the end date was chosen because it is around the time when the records were pulled from the court's digital databases. Most importantly, the follow-up period was chosen because it allowed for a fairly 
long period for tracking recidivism (Latessa, Listwan, \& Koetzle, 2014). The second inclusion criterion was that only a youth's initial OYAS-Disposition Tool assessment during the field period of the study was included. Any follow-up assessments were excluded. Finally, alt youth were required to have a follow-up period of 2 years to track recidivism (recidivism past the age of majority was included in this study for youth that aged out during the study). Anytyouth that were not tracked by the court for at least 2 years were excluded from the study. It is important to note that the collection of recidivism data extended to October 2017 to maximize the number of youth that had a 2-year follow-up period for recidivism.

\section{Study Participants}

Table 1 provides descriptive statistics for the youth in this sample. This table includes information on offense type, recidivism (measured as new petition), age, race, sex, and OYAS-Disposition Tool total and domain scores. Moreover, it lists this information separately for the full sample, subsample of sex offenders, and subsample of nonsex offenders. A total of 3,235 youth were included in the sample. As shown, $\sim 9 \%$ of youth had committed a sex offense. Less than half (48\%) of the youth in the full sample received a new petition in court within 2 years of their OYAS-Disposition Tool assessment. In terms of demographics, the majority of the sample was Black (66\%) and male (79\%) and the average age was 15.59 years old. The average total score on the OYAS-Disposition Tool was 12.04 (which falls into the moderate-risk category on the tool). Finally, all youth received probation, mandated programming, or a combination thereof as their disposition; none of the offenders received an institutional disposition but were placed under community supervision and supervised by juvenile probation officers.

\section{[Insert Table 1 Here]}


Table 1 also provides the same descriptive statistics for the subsample of sex and nonsex offenders. In addition, the final column in the table provides $t$-values or chi-square statistics that were estimated to examine variation across sex offender subgroups. Notably, there was significant variation between sex and nonsex offenders in every relationship examined.These results showed that sex offenders were less likely to receive a new court petition, younger, more likely to be White, and more likely to be male (the bivariate relationships between these two subgroups for the OYAS-Disposition Tool will be examined in the Results section).

\section{Measurement}

Recidivism. Reeidivism was measured in this study in two ways: as a new petition filed in court and as a new adjudication. A court petition is a formal document filed seeking intervention by the court. Court petitions in juvenile court can be filed by several interested parties such as police, prosecutors, parents, victims, and so on. Both of these measures of recidivism were cut off at 2 years so that all youth had an equal follow-up period.

An advantage of this study is that there are two measures of recidivism, which is important because there is considerable debate in the literature about the best way of measuring recidivism (Harris, Lockwood, \& Mengers, 2009). Therefore, it is beneficial to have multiple measures of recidivism available because convergence of results adds confidence to the validity of the findings.

Offense Type. Two steps were taken to code offense type in this study. First, only a youth's most serious charge was coded as his or her initial offense because many youth had multiple charges on their initial petitions in court. Second, every youth's most serious offense was categorized into one of two categories: sex and nonsex offenses. Sex offenses included 
crimes such as rape, sexual assault, molestation, and gross sexual imposition. Nonsex offenses included all other crimes.

OYAS-Disposition Tool. The OYAS-Disposition Tool (Latessa et al., 2009) is a $32-$ item actuarial risk assessment tool designed for use with a general population of offenders. Criminogenic risk is measured across a total of seven domains that include both historical and dynamic items. The seven domains include (1) juvenile justice history; (2) family and living arrangements; (3) peers and social support network; (4) education and employment; (5) prosocial skills; (6) substance abuse, mental health, and personality; and (7) values, beliefs, and attitudes. Examples of items in each domain include the number of previous adjudications, follows parent/caregiver's rules, importance of friends, quality of relationship with current school personnel or employer, pro-social decision-making skills, recent alcohol use, and procriminal sentiments. Thirty-one of the thirty-two items are scored dichotomously with the remaining item scored as a trichotomy. The total score of the tool is created by summing the score of the 32 items on the tool. Finally, the total score is categorized into one of three risk levels: low, moderate, or high. Cut-off scores differ for males and females. The cutoffs for males are as follows: low risk $=0-11$, moderate risk $=12-18$, and high risk $=19-33$. For females, they are low risk $=0-12$, moderate risk $=13-18$, and high risk $=19-33$.

Scoring the OYAS-Disposition Tool requires collecting information from several sources. The primary method to collect information is a face-to-face semistructured interview. The creators of the tool provide an interview guide that can be used to structure the interview. Other information is also collected in the form of a self-report survey filled out by the offender, a review of any available file information, and collection of collateral information from parties close to the offender (e.g., parents or teachers). Users of the tool are encouraged to triangulate information by applying multiple sources to ensure its accuracy. 
In addition, the OYAS-Disposition Tool permits users to override the risk level of the tool. Overrides are left to the discretion of the officer conducting the assessment. Overrides of risk level can occur in whichever direction the user sees fit (up or down), and there is no limit on the magnitude of the override that can be used (i.e., regardless of the risk level provided by the tool, the user can override to whichever other risk level he or she pleases). What is more, when officers use an override, they are required to provide written explanation to justify the use of it.

Certification is required to use the OYAS-Disposition Tool in practice. Two days of training and the passing of a final exam are needed. The final exam involves a written exam as well as scoring the tool based on a video of a fictitious interview. To pass, trainees must score at least $80 \%$ on the written exam and score the tool based on the video within a certain margin of error to the "true" score. Research findings show that trained officers can reliably score the tool in its entirety (Krippendorf's Alpha $=.81$ ) and all seven domains individually (the lowest Krippendorf's Alpha of any domain being .73; Latessa, Lux, \& Papp, 2018).

\section{Hypotheses}

Based on the research reviewed and the methods that have been discussed, the following hypotheses are offered:

1. Sex offenders will have significantly lower OYAS-Disposition Tool risk scores compared with those of nonsex offenders.

2. The OYAS-Disposition Tool will significantly predict reoffending for sex and nonsex offenders.

3. OYAS-Disposition Tool users will justify their use of discretionary overrides on the basis of the serious nature of sex crimes, departmental policy, and need to increase supervision/treatment dosage. 
4. Discretionary overrides will reduce the predictive validity of the OYAS-Disposition Tool.

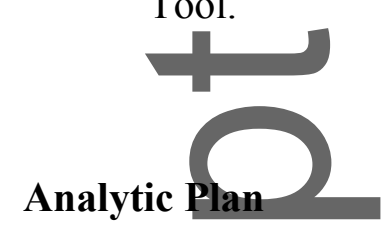

In this study, we primarily used AUC statistics and multinomial logistic regression to examine the predictive validity of the OYAS-Disposition Tool. AUC is a frequently used statistic in risk assessment research (Singh, Desmarais, \& Van Dorn, 2013). Similar to logistic regression, it is used by researchers to examine dichotomous dependent variables to determine the predictive power of a continuous independent variable. This analysis is advantageous in risk assessment because it is robust to low base rates and is nonparametric (Singh, Desmarais, \& Van Dorn, 2013). AUC statistics range from 0 to 1. Values less than or equal to .5 indicate that the variable's predictive power was less than or equal to chance, whereas values greater than .5 indicate prediction above chance levels.

In addition, multinomial logistic regression will be used for analyses in which direct comparisons are being made between the prediction of sexual and general recidivism, as compared with no recidivism (which will serve as the reference category). Multinomial regressionis used for the prediction of dependent variables that comprise more than two discrete outcomes, making it ideal for comparisons of multichotomous outcomes.

Multinomial logistic regression is used because it will allow for direct and clear comparisons to be made between the predictive validity of the tool for sexual and general recidivism.

\section{Results}

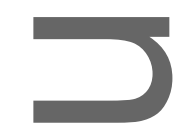

The first set of analyses included a series of $t$-tests and chi-square statistics to examine variation in the OYAS-Disposition Tool total and domain scores across subgroups of sex and nonsex offenders. These results are presented in Table 1 along with Cohen's $D$ effect sizes. 
Consistent with prior research findings, the results show that sex offenders scored significantly lower in terms of the total score and on all seven domains (all at a $p<.001$ level). The largest relative difference between sex and nonsex offenders was in the total score (Cohen's $D=1.00$ ). Sex offenders scored an average of 7.56 compared with 12.66 for nonsex offenders. Another large difference was in the peers domain where nonsex offender nearly doubled $(M=2.75)$ the score of sex offenders $(M=1.39)$, which resulted in a Cohen's $D$ of 87 .

\section{$\infty$}

\section{Recidivism Prediction}

Next, AUC statistics were estimated to examine the strength of the relationship between the total and domain scores of the OYAS-Disposition Tool and general recidivism (measured as a new petition within 2 years of the initial offense). Note that only the results for new petition are presented because the results for new adjudication as the outcome were substantively similar. Generat recidivism is measured here as a simple dichotomy of whether a youth received any new petition within 2 years of the date that he or she was assessed with the OYAS-Disposition Tool. Table 2 presents the AUC statistics for the whole sample, nonsex offenders, and sex offenders. The first two columns of Table 2 provide the AUC statistics and $95 \%$ confidenee intervals (CIs) for the whole sample. An AUC statistic of .63 for the total score shows that the OYAS-Disposition Tool predicts general recidivism at $\sim 13 \%$ above chance levels. Moreover, the education domain shared the strongest association with general recidivism $(A U C=.63)$, and the juvenile justice history domain shared the weakest association with general recidivism for the full sample $(A U C=.56)$.

[Insert Table 2 Here]

Table 2 also shows important differences in terms of predictive validity across subgroups. As can be seen, the AUC statistics for the total score was higher for the subsample 
of sex offenders $(A U C=.71)$ compared with for the subsample of nonsex offenders $(A U C=$ .63). In addition, the difference in these two effect sizes was statistically significant at a level of $p<.05$, which means that the OYAS-Disposition Tool is a much better predictor of general recidivism for sex offenders than for nonsex offenders [the formula from Hanley and McNeil (1982) was used to calculate a $Z$-statistic to test significance]. In addition, most domains were also significantly stronger predictors of general recidivism for sex offenders than for nonsex-offenders (all at least at a $p<.05$ level). These domains included history, peers, education, prosocial, substance, and values.

Table 3 shows the percentage of youth that recidivated by risk level for the whole sample, nonsex offenders, and sex offenders. These distributions are used to illustrate how the OYAS-Disposition Tool is outperforming for sex offenders. These results showed that the low-risk sex offenders had by far the lowest recidivism rate at $11.3 \%$ compared with $37.3 \%$ for nonsex offenders and $35.4 \%$ for the total sample, which is significant because sex offenders in the sample were low risk $(81.8 \%)$. The recidivism rate of moderate- and highrisk sex offenders $(50.0 \%$ and $75.0 \%$, respectively) is more comparable with that of nonsex offenders (55.9\% and 68.6\%, respectively).

[Insert Table 3 Here]

We used the last set of analyses on the predictive validity of the OYAS-Disposition Tool to examine the ability of the tool to predict sexual versus general recidivism. As this was a trichotomy (no recidivism, sexual recidivism, and general recidivism), multinomial logistic regression was used. Table 4 presents the results. In this table, nonrecidivists are the reference group for the dependent variable. After controlling for age and race (sex was omitted from the model because no females recidivated for a sexual offense), it can be seen that the total score of the OYAS-Disposition Tool is an effective predictor of both sexual [odds ratio $(O R)=1.22$ ] and general recidivism $(O R=1.26)$ for sex offenders. The total 
score, however, was only significantly predictive of general recidivism $(O R=1.10)$ for the subsample of nonsex offenders. It is important to note, though, that these findings should be approached with caution because of the very low base rate of sexual reoffending (out of the entire sample, only 24 youth reoffended with a sexual offense).

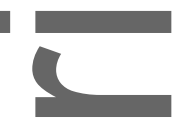

[Insert Table 4 Here]

\section{Override Decisions}

Next, override explanations were examined to understand the ways officers justified using them. Before discussing these explanations, it is important to note that $100 \%$ of overrides occurred in an upward direction. Therefore, all justifications that will be discussed were used to explain why the officers believed the OYAS-Disposition Tool was underestimating risk.

Two independent coders examined overrides and created coding schemes. A meeting was then held for the coders to discuss these themes. Once a unified coding scheme was created, two authors independently coded the responses. The initial kappa value on the independent coding was .8. The authors then met once more to discuss the discrepancies in coding decisions.

In regard to the explanations, some common themes were mentioned frequently. The most commonty used justification was the need for increased treatment dosage and/or the need for sex offender treatment. This was mentioned in $58.7 \%$ of all override justifications. The next most common justification was that the officer had also conducted a risk assessment designed specifically for sex offenders. This justification appeared in $49.1 \%$ of overrides. Some officers (7.1\%) further justified using a supplemental specialized assessment tool by mentioning that the OYAS-Disposition Tool had not been validated on sex offenders. Officers reported using the JSOAP and ERASOR as the specialized sex offender assessment tools. The nature of the offense was also mentioned as justifying the need for an override. For instance, $24.6 \%$ of officers cited the sexual nature of the offense as justifying the use of an 
override. Another $12.6 \%$ of officers mentioned the seriousness of the offense while not specifically stating that it was a sex offense. Finally, in a few instances (3.2\%), the officer mentioned that an override was needed because the youth lacked remorse and/or denied responsibility for his or her actions.

Finally, it was important to examine the frequency of overrides with sex offenders and the impact that overrides had on the predictive validity of the tool. Most sex offenders received an override $(57.3 \%)$, and there was evidence to suggest that this practice harmed the predictive validity of the OYAS-Disposition Tool when predicting general recidivism. For example, only $10.1 \%$ of low-risk sex offenders who received an override to moderate risk recidivated, which is substantially less than the $55.9 \%$ recidivism rate of moderate-risk nonsex offenders. Also, as shown in Table 5, the AUC statistic dropped in size when examining the relationship between risk level and general recidivism for sex offenders who did not receive an override $(A U C=.71)$ compared with those who did receive one $(A U C=$ .59). The AUC statistic of .59 for overridden cases was nonsignificant, which means that using overrides for sex offenders pushes the ability of the overridden risk level to predict general recidivism down to no better than chance levels. Moreover, the AUC statistic for the relationship between overridden risk level and sexual recidivism was nonsignificant at .48, which further shows that overrides are not accurately predicting recidivism.

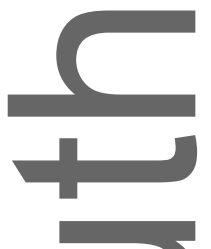

[Insert Table 5 Here]

\section{Discussion and Implications for Policy}

Corresponding with the study's hypotheses, the results indicated that the OYAS-Disposition Tool is a significant predictor of nonsexual recidivism for both sexual and nonsexual offenders. In fact, the OYAS-Disposition Tool significantly predicted sexual recidivism for sex offenders, although this was not the case for nonsexual offenders. What is more, the total 
score of the OYAS-Disposition Tool was a better predictor of general recidivism for sex offenders than it was for nonsex offenders. The findings from this study also corroborate those of prior research, which indicates that juvenile sex offenders score significantly lower than nonsex offenders on general risk assessments.

The findings in this study are consistent with those of past research showing that general riskassessment tools have utility with sex offenders (Seto \& Lalumiere, 2010). If further research results continue to support this finding, then the OYAS-Disposition Tool should serve jurisdictions interested in predicting general recidivism for sex offenders. The findings also show partial support for the tool's utility at predicting sexual recidivism and, therefore, have important implications for both policy and research on the topic of sexoffender risk assessment. First, past research on the efficacy of the model of the Central Eight was supported as a result of this study. As was predicted by the creators of the model (Bonta \& Andrews, 2016), the usefulness of risk assessment tools based on the Central Eight extend beyond generaloffenders and predict offending for specialized offenders as well. Even more interesting, the results in this study indicate that the Central Eight have utility in predicting sexual reoffending for sex offenders. This finding is important given the unique criminogenic risks and treatment factors measured on specific juvenile sex offender assessments (e.g., sexual drive, sexual aggression, and sexual victimization history). Ultimately, more research is needed to understand possible improvements that could be made to the prediction of sexual recidivism.

As it pertains to overrides, the hypotheses were also supported in regard to ways users of the OYAS-Disposition justified overrides. For instance, the most common justification for the use of overrides with sex offenders was the perceived need for increased treatment dosage. Interestingly, though, to date, no research findings indicate that sex offenders require increased treatment hours solely as a result of the nature of their offenses. The officers in the 
study, however, often used overrides for the sake of increasing treatment dosage for a subsample of youth made up mostly of low-risk offenders. Unfortunately, this goes against best practices in corrections, which follow the belief that treatment should not be provided (or provided in low doses) to low-risk offenders (Lowenkamp, Latessa, \& Holsinger, 2006). Therefore, discretionary practice has a negative impact on outcomes for youth and requires further research to understand how overrides influence outcomes in treatment and this effect on recidivism.

The second most common justification for overrides was the use and consideration of the results of a supplemental specialized sex offender assessment. What is more, some officers mentioned that the OYAS-Disposition Tool had not been validated on sex offenders, which is why they wanted to supplement with a tool that had been. This is encouraging because officers are taking into consideration research findings to inform their decisionmaking. Unfortunately, there are few findings available that can help inform the practice of using multiple risk assessments. For instance, no evidence would indicate exactly how multiple risk assessments could be incorporated to produce the best outcomes for youth. Furthermore, as the field of risk assessment evolves, researchers and practitioners should move toward aligning the information provided on risk assessments to specific programs and treatment plans, which may be difficult with multiple assessments that contain conflicting information.

Last, as hypothesized, the predictive validity of the OYAS-Disposition Tool was substantively reduced by the use of overrides. Overrides pushed particularly low-risk offenders into risk categories in which they were much less likely to reoffend compared with other offenders whose actual risk scores fell within those categories. This gives a false sense of the true risk that overridden youth pose for reoffending. These findings are unsurprising given that prior research results have consistently shown that actuarial methods far surpass 
other methods of assessment, especially professional judgment (Dawes, Faust, \& Meehl, 1989). Therefore, departmental policies designed to reign in professional discretion by careful monitoring may improve assessment and case management processes because the results from this study showed no clear benefit of using overrides.

\section{Limitations and Future Directions}

As this was the first examination of the OYAS-Disposition Tool for juvenile sex offenders, studies in other jurisdictions should be conducted in an attempt to determine the generalizability of the findings presented here. First, further research should also be aimed at examining the use of overrides in other jurisdictions. As mentioned, justifications for the use of overrides may vary significantly by jurisdiction because of prevailing policies and department philosophies/cultures. Second, the base rates for sexual recidivism in this study had an unclear effect on the results. Future research should be designed to prioritize large samples to obtain enough sexual recidivists to create stable analyses. Finally, in this study, we could not examine overrides that were from a higher risk level to a lower risk level as a result of the absence of this phenomenon in the data. Studies aimed at examining the extent to which this form of override is used with the OYAS-Disposition Tool or other tools may help build an understanding of the practice of overrides. Furthermore, in the event that overrides to a lower risk level are uncommon, techniques such as deviant case analyses exist to bolster knowledge on uneommon outcomes.

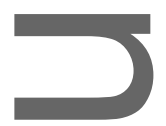

\section{Implications for Practice}

The findings from this study have several important policy implications that can be used to improve the assessment process of juvenile sex offenders. First, risk assessment practices can benefit from the adoption of general risk assessments that have been validated on specialized 
groups of offenders because general risk assessment tools typically assess a more diverse set of criminogenic risk and need factors (e.g., the Central Eight risk factors). Therefore, the case management process is improved by giving practitioners more targets for treatment and more information about the dosage of treatment needed, which is important as the findings from this and other studies show that sex offenders have a diverse range of criminogenic needs (Hanson \& Morton-Bourgon, 2005). Practitioners would be allowed to make more informed case management decisions by giving them information about the full range of criminogenic needs.

Following the first recommendation is also important because research results show that this practice improves the likelihood that practitioners will follow other best practices in correctional treatment, such as abiding by the principles of the risk-need-responsivity model (Lowenkamp et al, 2006). It is important to note, though, that caution should be taken against the use of general and specialized risk assessment tools in tandem as there was no evidence in this study to prove the efficacy of this approach. Continued research is needed on this topic because past findings are mixed about the effectiveness of combining the results of multiple actuarial methods as a result of the complexity that it can add to the decision-making process (Parent, Guay, \& Knight, 2011; Seto, 2005).

Second, changes are needed to reduce the negative impact that overrides had in this study. One improvement would be to restrict the proportion of sex offense cases that can be overridden. Research findings indicate that offense seriousness is not positively correlated with risk to reoffend (Baglivio, Greenwald, \& Russell, 2018; Latessa \& Lovins, 2010). In addition, specific training could be implemented that targets increasing a risk assessment user's knowledge of the use of a general assessment with specialized groups of offenders. Teaching risk assessment users how to negotiate the potential ambiguity in assessments is an 
integral next step in bridging the gap between practitioners and academia as it pertains to risk assessment training.

Third, agencies should consider validation research on specialized groups of offenders before full-implementation of a tool. Examination of the justifications for overrides in this study uncovered skepticism by OYAS-Disposition Tool users about the utility of the tool with sex offenders because they were aware that the tool had not been validated with this group. Therefore, the negative effect of increasing the rate of overrides for sex offenders likely resulted. Clearly, this would not have been the case had officers been presented with information showing that the tool is predictively valid for sex offenders. Implementing policy requiring more extensive validation research may increase officer buy-in and ultimately improve the implementation of the tool in practice.

Finally, adding to the previous recommendation for policy, validation research should occur at the jurisdictional level. McCafferty (2016) found that the validity of the OYASDisposition Toot varied across Ohio counties. More specifically, McCafferty found that the OYAS-Disposition Tool was significantly more predictive of recidivism in counties with higher crime rates. Other differences across jurisdictions, such as procedural differences (e.g., sex offender registration), may make it important to validate risk assessment tools at the jurisdictional level so that recommendations for policy can be made. Policies such as sex offender registries could be enacted to increase surveillance on sex offenders and make detection of recidivism more likely. If a sex offender assessment were validated in a jurisdiction that did not have a similar policy, this approach would be important as it could potentially impact the validity when used in a jurisdiction with different policies (Levenson \& Cotter, 2005)

Overall, although risk assessment research and practice have come a long way in the past several decades, improvements could still be made. Incremental changes to policy would 
improve the risk assessment process by more closely monitoring discretionary decisionmaking that we have shown to be detrimental. Reducing the problems with overrides that were found in this study would help to maintain the high levels of predictive validity found for the OYAS-Disposition Tool with sex offenders. Therefore, the case management process would ultimately improve and result in better outcomes for sex offenders involved with the juvenile justice system.

\section{References}

Baglivio, M. T., Greenwald, M. A., \& Russell, M. (2015). Assessing the implications of a structured decision- making tool for recidivism in a statewide analysis: Disposition matrix for court recommendations made by juvenile probation officers. Criminology \& Public Policy, 14(1), 5-49.

Baird, C., Healy, T., Johnson, K., Bogie, A., Dankert, E. W., \& Scharenbroch, C. S. (2013). A comparison of risk assessment instruments in juvenile justice. Report submitted to National Council on Crime and Delinquency, Madison, WI.

Baldwin, K. (2014). Sex offender risk assessment. Office of Sex Offender Sentencing, Monitoring, Apprehending, Registering, and Tracking. Retrieved from https://www.smart.gov/SOMAPI/contents.html\#adult

Barbaree, H., \& Marshall, W. (2008). The juvenile sex offender. New York, NY: Guilford Press.Bonta, J. (2002). Offender risk assessment: Guidelines for selection and use. Criminal Justice and Behavior, 29(4), 355-379.

Bonta, J., \& Andrews, D. A. (2016). The psychology of criminal conduct. Abingdon, England: Taylor \& Francis

Caldwell, M. F. (2010). Study characteristics and recidivism base rates in juvenile sex offender recidivism. International Journal of Offender Therapy and Comparative Criminology, 54(2), $197-212$

Campbell,C., Anderson, V., \& Papp, J. (2018). Juvenile sex offenders: Assessment. In R. Morgan (Ed.), The encyclopedia of criminal psychology. Thousand Oaks, CA: Sage.

Campbell,C., Papp, J., Barnes, A., Onifade, E., \& Anderson, V. (2018). Risk assessment and juvenile justice. An interaction between risk, race, and gender. Criminology \& Public Policy, 17(3), 525-545.

Carns, T., \& Martin, S. (2011). Does the YLS/CMI help to predict recidivism? An assessment of the Division of Juvenile Justice's use of the Youth Level of Services/Case Management Inventory. Report submitted to the Alaska Judicial Council and the Institute for Social and Economic Research, Anchorage, AK. 
Comartin, E. B., Kernsmith, P. D., \& Kernsmith, R. M. (2009). Sanctions for sex offenders: Fear and public policy. Journal of Offender Rehabilitation, 48(7), 605-619.

Dawes, R. M., Faulst, D., \& Meehl, P. E. (1989). Clinical versus actuarial judgment. Science, 243(4899), 1668-1674.

Desmarais, S. L., \& Singh, J. P. (2013). Risk assessment instruments validated and implemented in correctional settings in the United States. New York, NY: Council of State Governments Justice Center.

Guay, J-P.\& Parent, G. (2018). Broken legs, clinical overrides, and recidivism risk: An analysis of decisions to adjust risk levels with the LS/CMI. Criminal Justice and Behavior, 45(1), 82100 .

Hanley, J. Al, \&McNeil, B. J. (1982). The meaning and use of the area under a Receiver Operating Characteristic (ROC) curve. Radiology, 143(1), 29-36.

Hanson, K.R., \&Bussiere, M. (1998). Predicting relapse: A meta-analysis of sexual offender recidivism studies. Journal of Consulting and Clinical Psychology. 66(2), $348-362$.

Hanson, K. R., \& Morton-Bourgon, K. E. (2005). The characteristics of persistent sexual offenders: A meta-analysis of recidivism studies. Journal of Consulting and ClinicalPsychology, 73(6), 1154.

Harris, P., Lockwood, B., \& Mengers, L. (2009). Defining and measuring recidivism (White paper). Braintree, MA: Council of Juvenile Correctional Administrators.

Helmus, L., Hanson, K. R., Thornton, D., Babchishin, K. M., \& Harris, A. J. (2012). Absolute reeidivism rates predicted by Static-99R and Static-2002R sex offender risk assessment tools vary across samples: A meta-analysis. Criminal Justice and Behavior, 39(9), $1148-1171$.

Hoge, R. D., \& Andrews, D. A. (2011). Youth Level of Service/Case Management Inventory 2.0 YLS/CMI 2.0): User's manual. Toronto, Ontario, Canada: Multi-Health Systems.

Judge, J., Quayle,E., O'Rourke, S., Russell, K., \& Darjee, R. (2014). Referrers' views of structured professional judgement risk assessment of sexual offenders: A qualitative study. Journal of Sexual Aggression, 20(1), 94-109.

Knight, R.A., \& Sims- Knight, J. E. (2003). The developmental antecedents of sexual coercion against women: Testing alternative hypotheses with structural equation modeling. The ANNALS of the New York Academy of Sciences, 989(1), 72-85.

Latessa, E. J., Listwan, S. L., \& Koetzle, D. (2014). What works (and doesn't) in reducing recidivism. New York, NY: Routledge.

Latessa, E.J., \& Lovins, B. (2010). The role of offender risk assessment: A policy maker guide. Victims \& Offenders, 5(3), 203-219.

Latessa, E. J., Lovins, B., \& Lux, J. (2014). Evaluation of Ohio RECLAIM programs. Report submitted to the Ohio Department of Youth Services, Columbus, OH. 
Latessa, E. J., Lovins, B., \& Ostrowski, K. (2009). The Ohio Youth Assessment System: Final report. Cincinnati, $\mathrm{OH}$, University of Cincinnati: Center for Criminal Justice Research.

Latessa, E. J., Lux, J., \& Papp, J. (2018). Validation of the Arizona Youth Assessment System. Report submitted to the Arizona Juvenile Probation Services, Phoenix, AZ.

Lawing, K. Childs, K. K., Frick, P. J., \& Vincent, G. (2017). Use of structured professional judgment by probation officers to assess risk for recidivism in adolescent offenders. Psychological Assessment, 29(6), 652.

Levenson,J.S. (2008). Collateral consequences of sex offender residence restrictions. Criminal Justice Studies, 21(2),153-166.

Levenson, J.S., Brannon, Y. N., Fortney, T., \& Baker, J. (2007). Public perceptions about sex offenders and community protection policies. Analyses of Social Issues and Public Policy, 7(1), 137-161.

Levenson,J.S., \& Cotter, L. P. (2005). The effect of Megan's Law on sex offender reintegration. Journal of Contemporary Criminal Justice, 21(1), 49-66.

Lovins, B. \& Latessa, E. (2013). Creation and validation of the Ohio Youth Assessment System (OYAS) and strategies for successful implementation. Justice Research and Policy, $15(1), 67-93$.

Lowenkamp, C. T, Latessa, E. J., \& Holsinger, A. M. (2006). The risk principle in action: What have we learned from 13,676 offenders and 97 correctional programs?. Crime \& Delinquency, 52(1), 77-93.

Mancini, C., \& Mears, D. P. (2010). To execute or not to execute? Examining public support for capital punishment of sex offenders. Journal of Criminal Justice, 38(5), 959-968.

McCafferty, J. T. (2013). The predictive validity of the Ohio Youth Assessment SystemDisposition Instrument: A revalidation study (Dissertation). University of Cincinnati.

McCafferty, J. T. (2016). The importance of counties: Examining the predictive validity of a state juvenile risk assessment instrument. Journal of Offender Rehabilitation, 55(6), $377-395$

Olver, M. E., Stoekdale, K. C., \& Wormith, J. S. (2009). Risk assessment with young offenders: A meta-analysis of three assessment measures. Criminal Justice and Behavior, 36(4), 329-353.

Orbis Partners. (2007). Long-term validation of the Youth Assessment and Screening Instrument (YASY) in New York state juvenile probation. Report submitted to New York State Division of Probation and Correctional Alternatives, New York, NY.

Parent, G., Guay, J-P., \& Knight, R. A. (2011). An assessment of long-term risk of recidivism by adult sex offenders: One size doesn't fit all. Criminal Justice and Behavior, 38(2), 188209.

Pew Charitable Trust. (2015). States slowly scale back juvenile sex offender registries. Retrieved from https://www.pewtrusts.org/en/research-andanalysis/blogs/stateline/2015/11/19/states-slowly-scale-back-juvenile-sex-offender-registries 
Prentky, R. A., \& Righthand, S. (2003). Juvenile Sex Offender Assessment Protocol-II (JSOAP-II). Washington, DC: U.S. Department of Justice, Office of Justice Programs, Office of Juvenile Justice and Delinquency Prevention.

Ragusa-Salerno, L. M., Ostermann, M., \& Thomas, S. S. (2013). Does the LSI-R have utility for sex offenders? Criminal Justice and Behavior, 40(9), 952-969.

Sahlstrom, K. J., \& Jeglic, E. L. (2008). Factors affecting attitudes toward juvenile sex offenders. Journal of Child Sexual Abuse, 17(2), 180-196.

Schwalbe, C.S. (2007). Risk assessment for juvenile justice: A meta-analysis. Law and Human Behavior, 31(5), 449-462.

Schwalbe, C.S. (2008). A meta-analysis of juvenile justice risk assessment instruments predictive validity by gender. Criminal Justice and Behavior, 35(11), 1367-1381.

Seto, M. C. (2005). Is more better? Combining actuarial risk scales to predict recidivism among adult sex offenders. Psychological Assessment, 17(2), 156.

Seto, M. C., \& Lalumiere, M. L. (2010). What is so special about male adolescent sexual offending? Psychological Bulletin, 136(4), 526-575.

Singh, J. P., Desmarias, S. L., \& Van Dorn, R. A. (2013). Measurement of predictive validity in violence risk assessment studies: A second-order systematic review. Behavioral Sciences and the Law, 31(1), 55-73.

Tully, R. J., Chou, S., \& Browne, K. D. (2013). A systematic review on the effectiveness of sex offender risk assessment tools in predicting sexual recidivism of adult male sex offenders.

Clinical Psychology Review, 33(2), 287-316.

Viljoen, J.L., Mordell, S., \& Beneteau, J. L. (2012). Prediction of adolescent sexual reoffending: A meta-analysis of the J-SOAP-II, ERASOR, J-SORRAT-II, and Static-99. Law and Human Behavior, 36(5), 423.

Worling, J. R. (2004). The Estimate of Risk of Adolescent Sexual Offense Recidivism (ERASOR):Preliminary psychometric data. A Journal of Research and Treatment, 16(3), 235254.

Worling, J. R., \& Curwen, T. (2000). Adolescent sexual offender recidivism: Success of specialized treatment and implications for risk prediction. Child Abuse \& Neglect, 24(7), 965982.

Worling, J.R., \& Langstrom, N. (2008). Risk of sexual recidivism in adolescents who offend sexually. In H. Barbaree \& W. Marshall (Eds.), The juvenile sex offender. New York, NY: Guilford Press.

Wormith, S. J, Hogg, S., \& Guzzo, L. (2012). The predictive validity of a general risk/needs assessment inventory on sexual offender recidivism and an exploration of the professional override. Criminat Justice and Behavior, 39(12), 1511-1538. 
Jordan Papp

Jordan Papp is a doctoral student in the School of Criminal Justice at the University of Cincinnati. He is currently a project manager at the Institute for Social Research at the University of Michigan. His research interests include corrections, risk assessment, and juvenile justice.

\section{Christina Campbell}

Christina A. Campbell is an Assistant Professor at the University of Cincinnati in the School of Criminal Justice. Her primary research interests include delinquency prevention, risk assessment, juvenile justice policy, and neighborhood ecology. She also conducts research on racial and health disparities experienced by individuals who come in contact with the criminal justice and child welfare systems. She is a NIJ W.E.B. Dubois research fellow.

William T. Milfer

William T. Miller is a doctoral student at the University of Cincinnati School of Criminal Justice. His primary research interests include recidivism risk assessment, program evaluation, and offender treatment. He also conducts research on strategies to increase therapeutic engagement in mandated programming with offending populations.

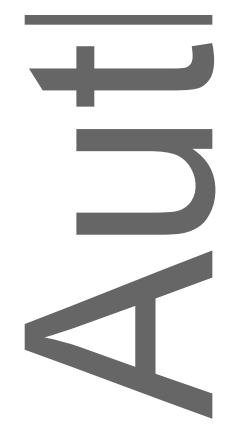


Table 1. Descriptive Statistics and Mean Difference Tests $(N=3,235)$

\begin{tabular}{|c|c|c|c|c|c|c|c|c|c|c|}
\hline \multirow[t]{2}{*}{ Variable } & \multicolumn{2}{|c|}{ Full Sample } & \multicolumn{3}{|c|}{ Sex Offenders } & \multicolumn{3}{|c|}{ Nonsex Offenders } & \multirow[b]{2}{*}{$t$ or $\chi^{2}$} & \multirow[b]{2}{*}{$\begin{array}{c}\text { Cohe } \\
\text { n D }\end{array}$} \\
\hline & $\%$ & SD & $M$ & $\%$ & SD & $M$ & $\%$ & SD & & \\
\hline $\begin{array}{l}\text { Sex } \\
\text { Offender }\end{array}$ & 8,84 & - & - & - & - & - & - & - & - & - \\
\hline $\begin{array}{l}\text { New } \\
\text { Petition } \\
\text { for Sex } \\
\text { Offense }\end{array}$ & 1.00 & - & - & 2.91 & - & - & .56 & - & - & - \\
\hline $\begin{array}{l}\text { New } \\
\text { Petition } \\
\text { for Any } \\
\text { Offense }\end{array}$ & $\begin{array}{c}48.2 \\
1\end{array}$ & - & - & $\begin{array}{c}19.1 \\
7\end{array}$ & - & - & $\begin{array}{c}50.4 \\
8\end{array}$ & - & $\begin{array}{c}86.04^{* *} \\
*\end{array}$ & .69 \\
\hline Black & $\begin{array}{c}66.4 \\
0\end{array}$ & - & - & $\begin{array}{c}56.7 \\
4\end{array}$ & - & - & $\begin{array}{c}67.6 \\
0\end{array}$ & - & $\begin{array}{c}13.62 * * \\
*\end{array}$ & .23 \\
\hline Male & $\begin{array}{c}79.3 \\
0\end{array}$ & - & - & $\begin{array}{c}89.5 \\
1\end{array}$ & - & - & $\begin{array}{c}79.5 \\
8\end{array}$ & - & $\begin{array}{c}16.35^{* *} \\
*\end{array}$ & .28 \\
\hline Age & - & $\begin{array}{c}1.5 \\
3\end{array}$ & $\begin{array}{c}15.2 \\
5\end{array}$ & - & $\begin{array}{c}1.6 \\
3\end{array}$ & $\begin{array}{c}15.5 \\
8\end{array}$ & - & $\begin{array}{c}1.5 \\
2\end{array}$ & $3.28 * *$ & .21 \\
\hline $\begin{array}{l}\text { Total } \\
\text { Score }\end{array}$ & - & $\begin{array}{c}5.6 \\
5\end{array}$ & 7.56 & - & $\begin{array}{c}4.5 \\
0\end{array}$ & $\begin{array}{c}12.6 \\
6\end{array}$ & - & $\begin{array}{c}5.5 \\
8\end{array}$ & $\begin{array}{c}17.86^{* *} \\
*\end{array}$ & 1.00 \\
\hline Domains & & & & & & & & & & \\
\hline History & - & .99 & .58 & - & .83 & .90 & - & $\begin{array}{c}1.0 \\
1\end{array}$ & $6.16^{* * *}$ & .35 \\
\hline Family & - & $\begin{array}{c}1.6 \\
1\end{array}$ & 1.12 & - & $\begin{array}{c}1.2 \\
5\end{array}$ & 2.14 & - & $\begin{array}{c}1.6 \\
2\end{array}$ & $\begin{array}{c}12.74^{* *} \\
*\end{array}$ & .70 \\
\hline Peers & - & $\begin{array}{c}1.7 \\
4\end{array}$ & 1.39 & - & $\begin{array}{c}1.3 \\
5\end{array}$ & 2.75 & - & $\begin{array}{c}1.7 \\
3\end{array}$ & $\begin{array}{c}15.78^{* *} \\
*\end{array}$ & .87 \\
\hline Educatio & - & $\begin{array}{c}1.0 \\
7\end{array}$ & 1.43 & - & $\begin{array}{c}1.1 \\
0\end{array}$ & 2.19 & - & $\begin{array}{c}1.0 \\
5\end{array}$ & $\begin{array}{c}11.27 * * \\
*\end{array}$ & .71 \\
\hline Prosocia & - & $\begin{array}{c}1.1 \\
5\end{array}$ & 1.23 & - & $\begin{array}{c}1.0 \\
9\end{array}$ & 1.77 & - & $\begin{array}{c}1.1 \\
2\end{array}$ & $7.74 * * *$ & .49 \\
\hline $\begin{array}{l}\text { Substanc } \\
\mathrm{e}\end{array}$ & - & $\begin{array}{c}1.2 \\
5\end{array}$ & 1.15 & - & .92 & 1.85 & - & $\begin{array}{c}1.2 \\
5\end{array}$ & $\begin{array}{c}11.77^{* *} \\
*\end{array}$ & .64 \\
\hline
\end{tabular}




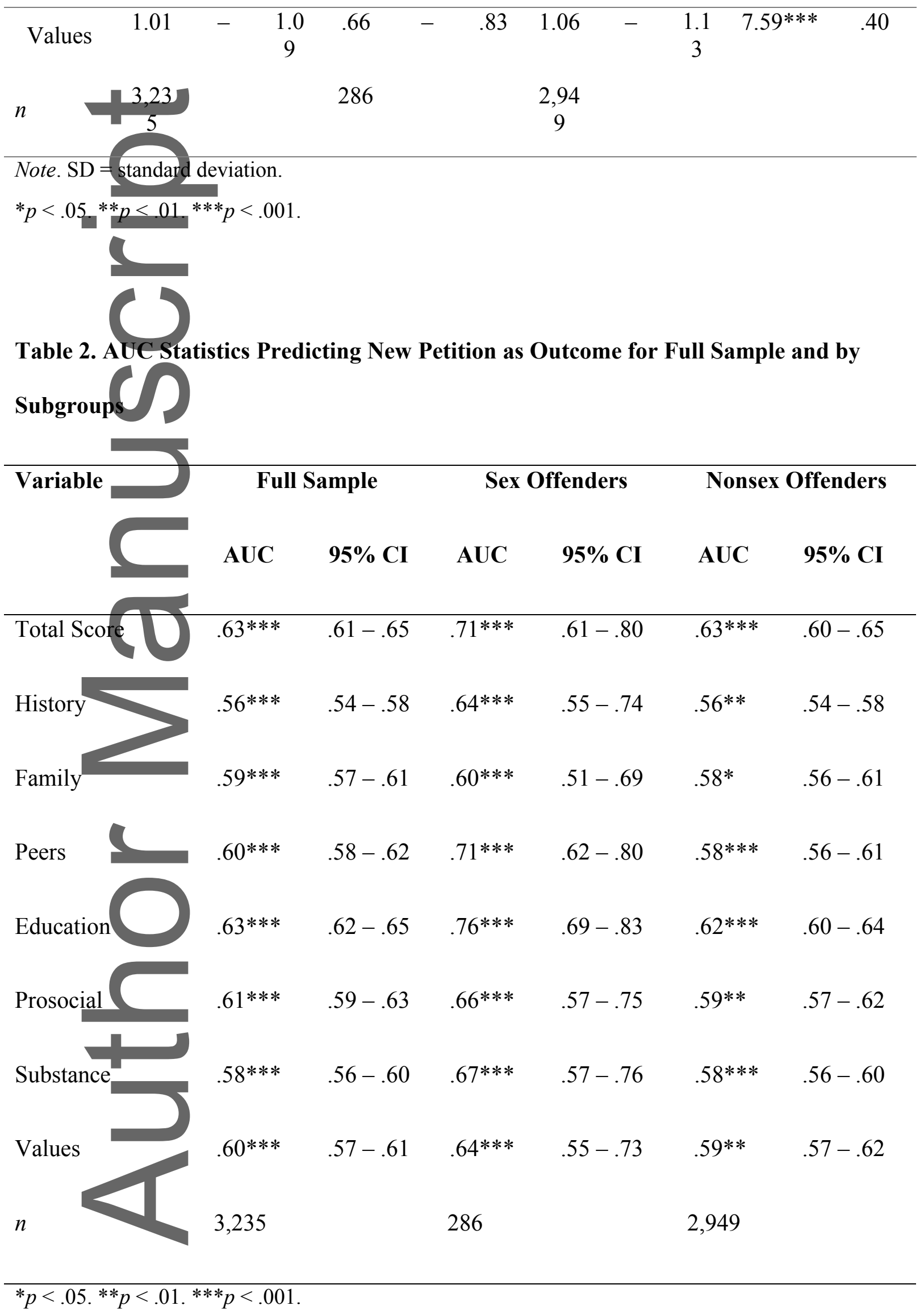


Table 3. New Petition Rates by OYAS-Disposition Tool Risk Level for Full Sample and by Subgroups

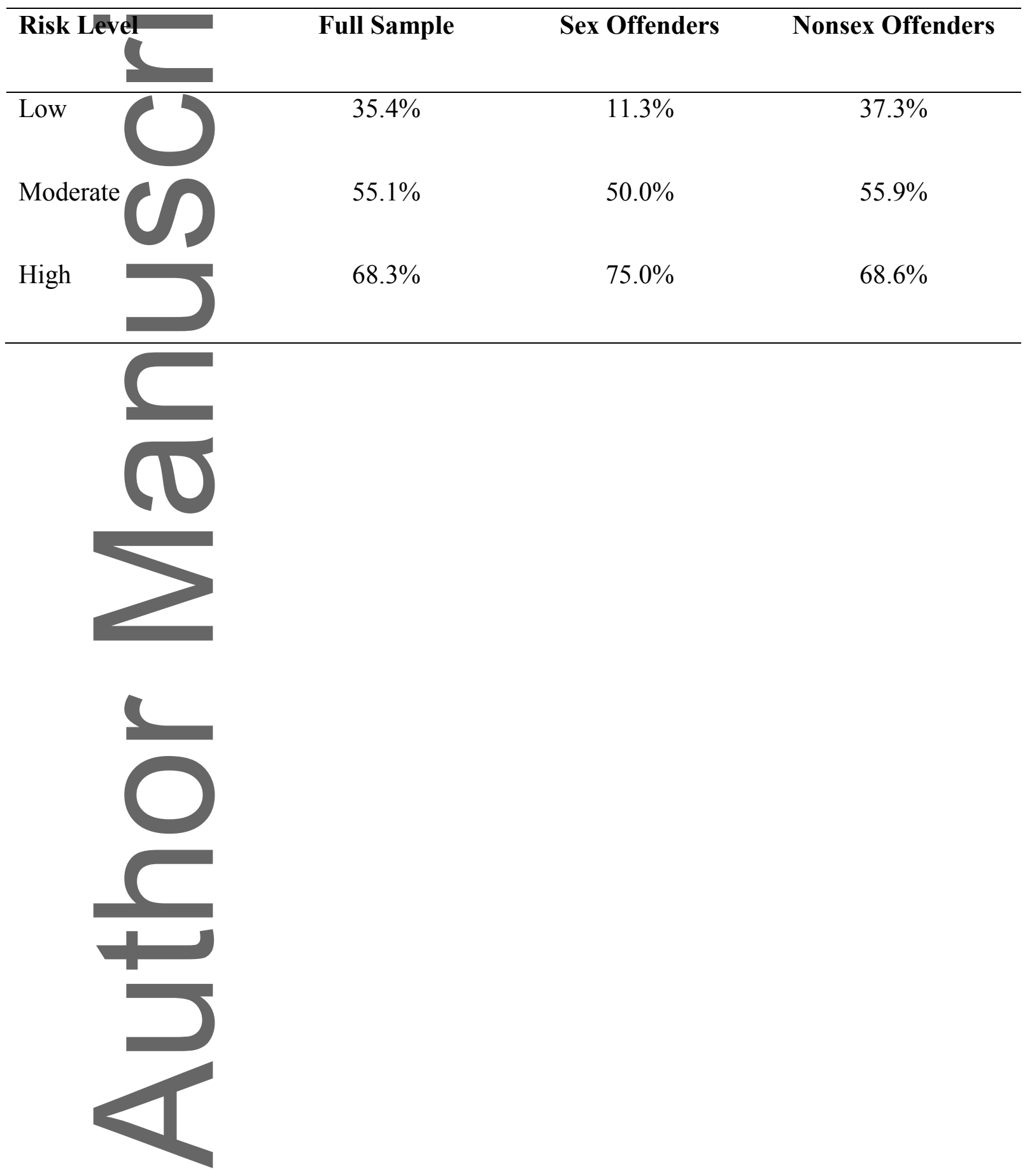


Table 4. Multinomial Logistic Regression Predicting Sexual and General Recidivism ( $=\mathbf{3 , 2 3 5 )}$

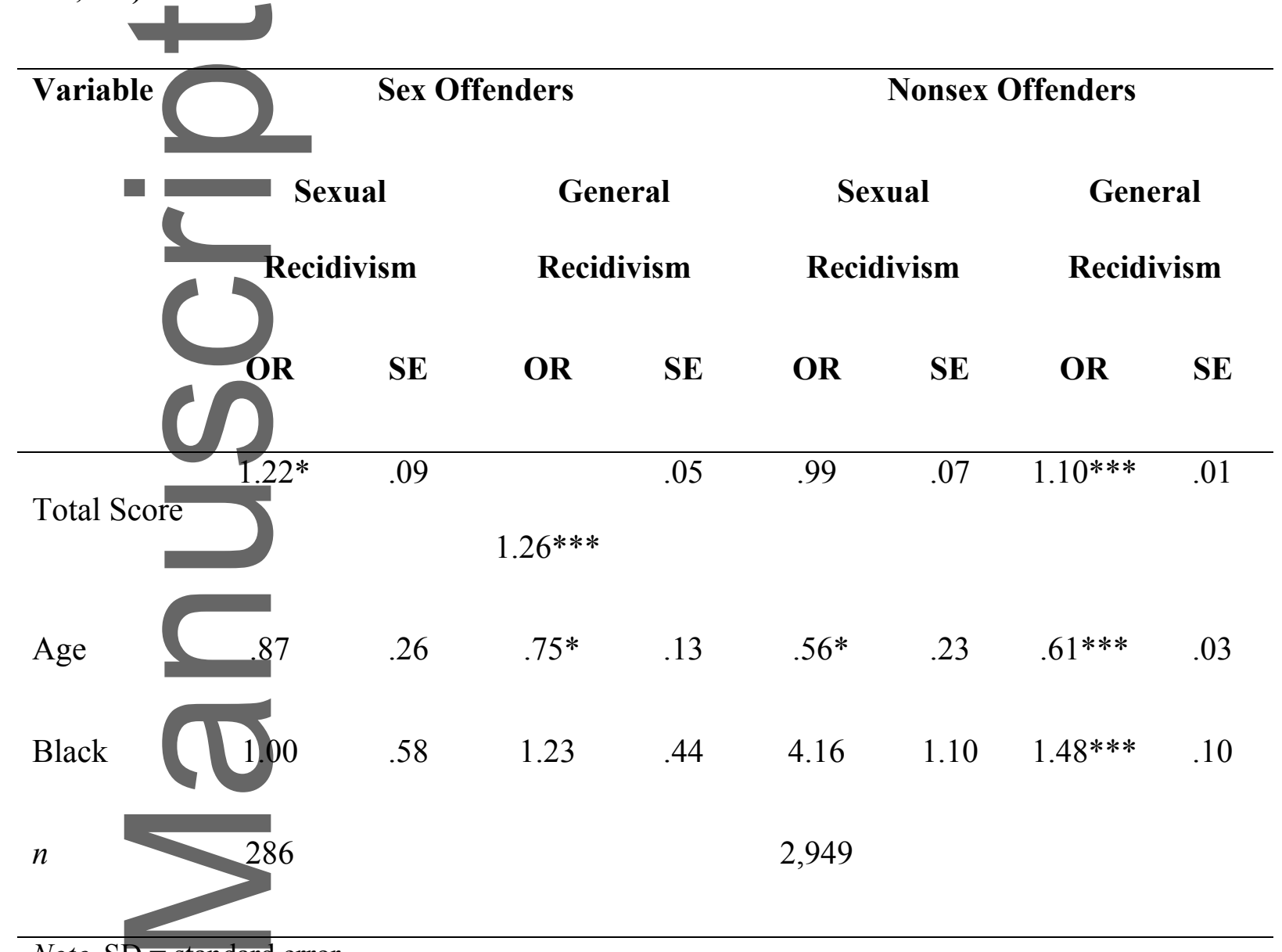

Note. $\mathrm{SD}=$ standard error.

$*_{p}<.05 . * * p<.01 . * * * p<.001$.

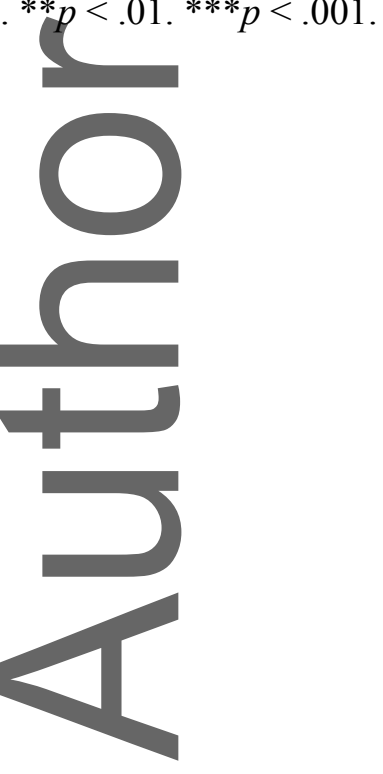


Table 5. AUC Predicting General and Sexual Recidivism

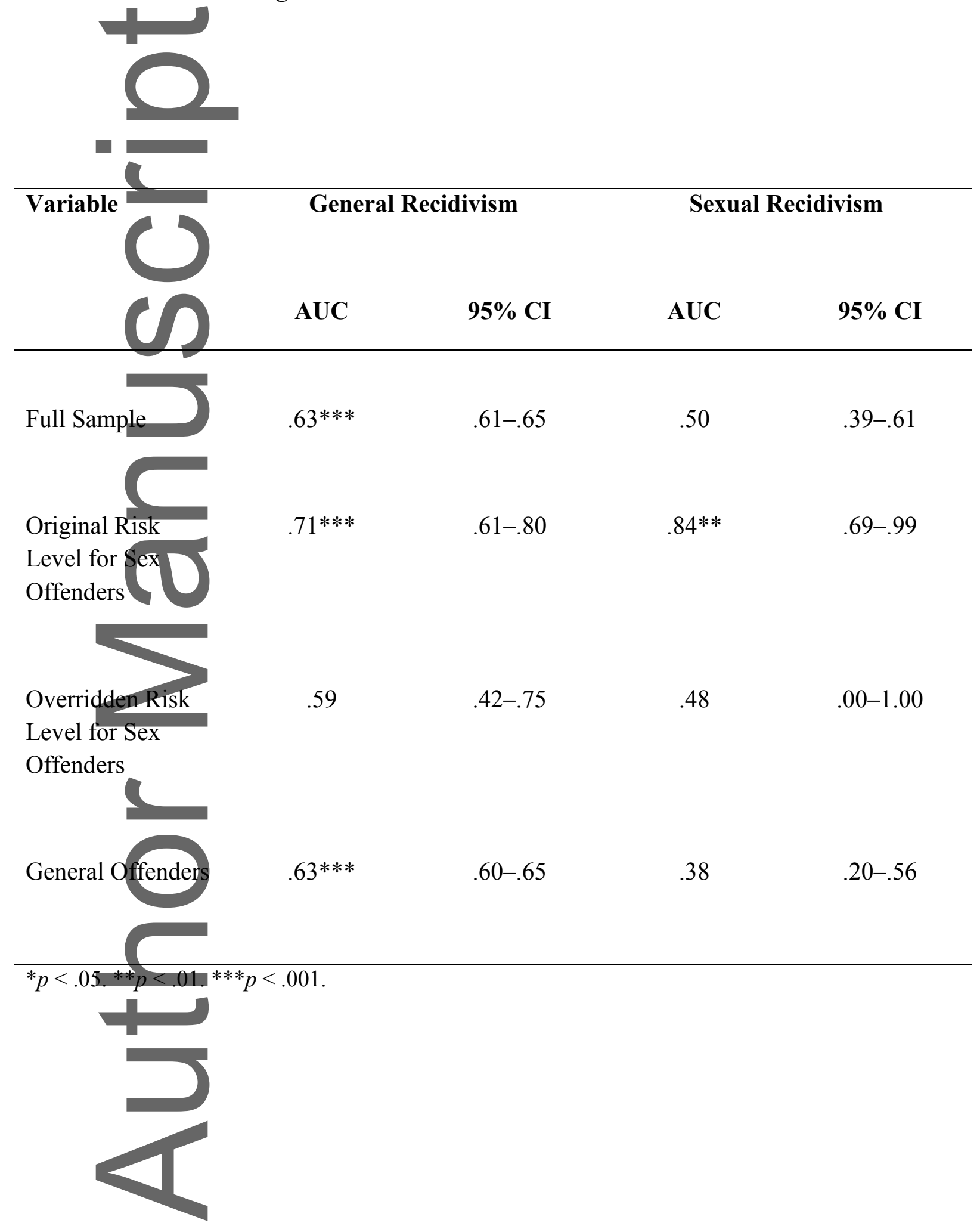

This article is protected by copyright. All rights reserved. 